\title{
Improving the Adoption and Use of Planning Support Systems in Practice
}

\author{
Guido Vonk • Stan Geertman
}

Received: 27 November 2007 / Accepted: 11 June 2008 /

Published online: 16 July 2008

(C) The Author(s) 2008

\begin{abstract}
Planning Support Systems (PSS) are geo-information based tools intended to support planners in planning tasks such as information handling, communication and analysis in planning processes. They can be useful tools in helping planners to handle the ever-increasing complexity of planning. However, PSS technology is trapped in a vicious circle created by the large mismatch that exists between the supply of and the demand for PSS. Despite their many promising characteristics, PSS have not yet become widely used in planning practice; lessons must be learned on how to effectively develop and apply PSS. Without such experience, it becomes difficult to pursue the improvement of PSS technology, which in turn means fewer lessons can be learned. This paper aims to narrow the gap between supply and demand by providing lessons for planners, PSS developers and researchers of PSS development and use.
\end{abstract}

Keywords Planning support systems $\cdot$ PSS $\cdot$ Bottlenecks $\cdot$ Lessons $\cdot$ Planning

\section{Introduction}

Urban planning concerns the design and organisation of urban physical and socioeconomic space and the measures undertaken to solve existing problems and/or anticipate future problems. The general objective is usually to provide for an organisation of activities (or of urban space) which in some way is better than the

G. Vonk $(\bowtie)$

Alterra, Wageningen University and Research Center, P.O. Box 47, 6700 AA Wageningen, The Netherlands

e-mail: g.a.vonk@gmail.com

S. Geertman

Urban and regional Research center Utrecht, University of Utrecht, P.O. Box 80115, 3508 TC Utrecht, The Netherlands

e-mail: s.geertman@geo.uu.nl 
pattern existing without planning (Hall 1975). This objective is usually achieved by using knowledge and creativity to design, evaluate and implement a set of justified actions in the public domain (Friedman 1987). The knowledge consists of scientific and experiential knowledge, implicit and explicit knowledge, technical knowledge and social knowledge, possessed by a number of societal actors (Dammers et al. 1999). When these actors enter the planning arena their knowledge is used to put actions into an orderly sequence to deliberately achieve the planning objective (Hall 1975). Juggling the various types of knowledge in the multi-actor arena of urban planning can be challenging. Knowledge must first be available to inform the participants. Then it must be communicated between the participants and analysed to ensure that underlying patterns in the knowledge that are relevant to the planning problem and its solution become evident. Currently, urban planners experience difficulties in handling knowledge appropriately, and the lack of attention to knowledge has led to large planning failures on occasions (Stillwell et al. 1999; In 't Veld 2000).

Geo-information technology developers have long focused on supporting urban planners in handling knowledge and information. Information management support and scenario analysis have received a great deal of attention in particular. Nonetheless, the large-scale urban models of the 1960s and 1970s have failed to meet the expectations and have not become widely accepted as planning support instruments (Lee 1973; Batty 1979; Openshaw 1979; Lee 1994). Nor have the Geographical Information Systems (GIS) of the 1980s and 1990s become widely used for typical planning tasks, such as scenario generation and the evaluation of alternatives (Croswell 1991; Innes and Simpson 1993; Stillwell et al. 1999). Although many planners use them for basic information functions, most GIS are general-purpose tools that are insufficiently suited to the specific demands and capabilities of planners in planning processes. Many of the Spatial Decision Support Systems (SDSS) of the 1990s have also failed to become widely implemented in planning practice (Geertman and Stillwell 2003).

A new generation of geo-information technologies known as Planning Support Systems (PSS) is much more dedicated to the specific demands and capabilities of planners in planning processes (Geertman and Stillwell 2004). These PSS may be better suited to assisting planners in handling knowledge in planning. They have been defined as a subset of geo-information technologies dedicated to supporting those involved in planning in exploring, representing, analysing, visualising, predicting, prescribing, designing, implementing, monitoring and discussing issues associated with the need to plan (Batty 1995). PSS combine the functionalities of GIS with models and visualisation. They function as "information frameworks" that integrate the full range of information technologies useful for supporting the specific planning context for which they are designed (Klosterman 1997; Geertman and Stillwell 2003). Inventories show that PSS cover a wide range of tools that are readily available for planning support purposes. With respect to knowledge handling, these can be divided into instruments to support the provision of knowledge to those involved in planning, instruments to support communication of knowledge and systems to support knowledge analysis.

Despite the many promising characteristics of PSS, PSS technology is trapped in a vicious circle (Fig. 1) caused by the large mismatch that exists between supply of 


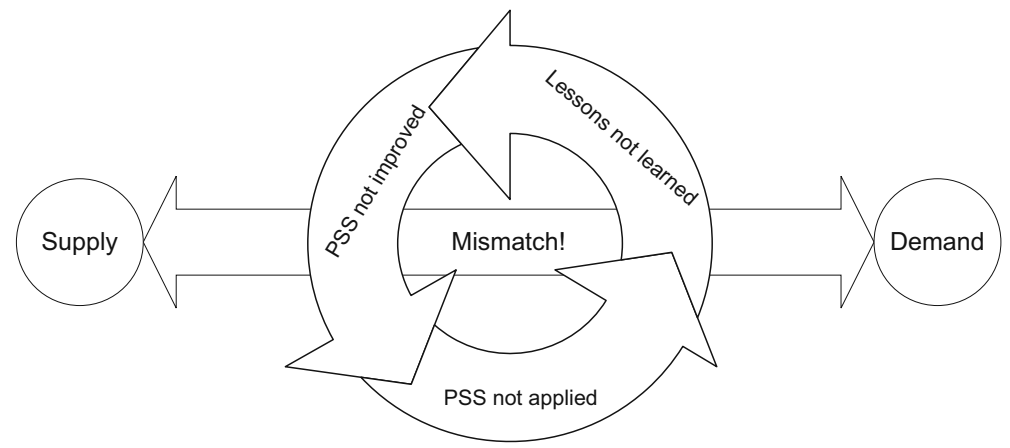

Fig. 1 Vicious circle of PSS application in practice, caused by the mismatch between the demand for and the supply of PSS

and demand for PSS. Although there are many PSS in existence, generally speaking PSS have not yet become widely applied in planning practice (Brail and Klosterman 2001; Geertman and Stillwell 2003). As a result few lessons are actually being learned about the effective integration of PSS in planning practice, and this lack of experience hampers the further improvement of PSS technology and its application. This vicious circle is problematic in that more effective integration of PSS in planning practice could possibly improve planning. Many experts see PSS as capable of supporting planners in developing well-founded plans for an increasingly complex socio-physical environment in increasingly complex planning process environments. From this perspective, PSS could save planners time and money as well as improve the quality of their work.

The current study aims to present lessons that demonstrate the effective integration of PSS in planning practice. They can help to break the vicious circle that constrains PSS technology and reduce the discrepancy between supply of and demand for PSS. With this goal in mind, we begin by describing our research strategy and method. Second, we present important bottlenecks that are responsible for the mismatch between supply of and demand for PSS. Third, we describe a range of empirical lessons that may be applied to remove these bottlenecks. Some of the lessons may also apply to SDSS and other related categories of planning tools that have a much longer history and have the same implementation problems as PSS.

\section{Research Strategy and Method}

Strategy

Several studies have tried to explain the mismatch between the supply of and demand for PSS from three perspectives. The first concerns the quality of the PSS themselves, specifically the extent to which PSS match up with the characteristics of the actual planning tasks and intended users. The second concerns their diffusion to planning practice while the third perspective looks at acceptance of PSS by the 


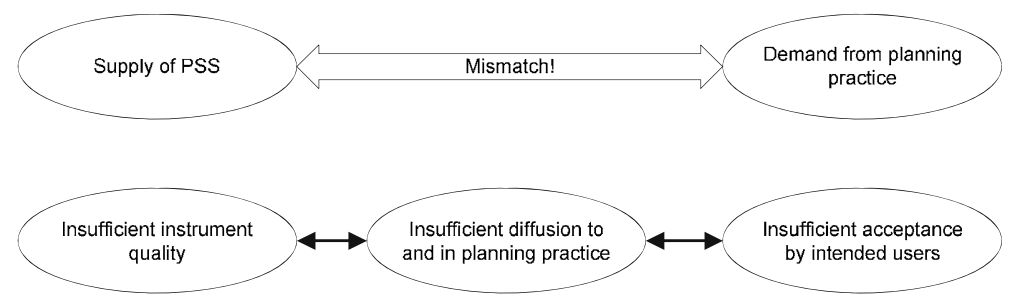

Fig. 2 Three perspectives to study the supply of and the demand for PSS

intended users (Vonk et al. 2006). These three categories are related since poor instrument quality is likely to hinder diffusion and user acceptance. Limited diffusion and user acceptance can also obstruct the instrument quality of PSS since practical lessons are needed at the development stage. We expect supply-side research to be more strongly focused on instrument quality whereas demand-side research is likely to focus more on diffusion and user acceptance. Figure 2 shows the three perspectives used to study supply and demand of PSS.

\section{Method}

In our empirical research, bottlenecks are apparent that hinder the widespread use of PSS and there are lessons that can be applied to remove these bottlenecks. We approach these bottlenecks and solutions from the three perspectives described above in our research strategy, drawing upon various sources of knowledge and expertise (PSS users, developers and experts), using a range of research methods to do so (interviews, literature study, web surveys).

User views of PSS have been collected by conducting interviews with 43 employees of 12 Dutch regional planning organisations dedicated to regional strategic land-use planning. Their key tasks are to develop plans for water, traffic, environment, economy etc, and to integrate these into a comprehensive structure plan for the area under their jurisdiction. Our interviews were held with three archetypes of users in particular that currently fulfil an important role in PSS usage: the geo-information specialist, the planner and the manager. These three types provide a representative overview of user perspectives on PSS technology in most societies in the developed world. This is supported by evidence suggesting the existence of more or less similar planning organisational environments in these societies (Anthony 1965; Minzberg 1981; Borins 2000, 2001). Our study does not distinguish specific aspects of the planning style in particular countries. We are fully aware that planning processes involve societal actors such as land and property developers, community groups and other stakeholders other than employees of planning organisations. However, these societal actors were not included in our research because planning processes are normally initiated by planning organisations, and our aim is to find out why people in planning organisations do or do not use PSS. Where relevant, employees of planning organisations were assumed to be fully capable of reporting the views of the other societal actors they encounter in planning practice. In the end, the interviewees included 15 geo-information specialists, 12 planners and three managers, but also included 13 people with other 
relevant specialisations such as environmental planning, economic planning, social planning and general IT. The interviews were carried out in groups during 12 sessions of several hours each.

PSS system developer views of PSS have been well recorded in the scientific literature. Because of this, we pinpointed their perspectives of the compatibility of PSS with planning tasks and users in planning practice through a literature survey. For the selection of suitable literature, we applied the definition of PSS as given in the introduction. This definition is relatively broad, but allows for the diversity in views among experts about the content of the PSS concept. We also limited the review to literature published after 1998 in order to account for the shifting meaning of PSS with advancing technological possibilities. Books on PSS, papers from conferences and journals on geographic information science were included although the two main sources were edited collections on PSS by Brail and Klosterman (2001) and Geertman and Stillwell (2003). A total of 58 views on PSS were included, constituting a fair overview of system developer perspectives on tasktechnology-user fit of PSS.

Furthermore, expert views of PSS have been compiled by means of two worldwide web surveys. Through several PSS-related listserv e-mail networks, 800 persons interested in PSS were asked to participate. The first survey drew 96 respondents and the second 40. Eighty-six of the 96 and 30 of the 40 respondents were considered experts as they stated that they were familiar with at least two PSS from a list provided. The majority of the expert respondents were university researchers or employees of public planning agencies dealing with planning support in their work. Although many users from planning practice were asked to participate, they were a minority among the respondents. The first survey revealed a series of bottlenecks that could potentially obstruct the widespread usage of PSS; these were rated accordingly by the experts. The second survey consisted of open questions about the strengths, weaknesses, opportunities for and threats to PSS. This survey also included closed questions concerning the perceived fit of a range of combinations of planning tasks, PSS and users and required respondents to rate the level of their experience with these combinations. Respondents could rate the importance of potential bottlenecks as well as the fit by choosing between 'not useful', 'neutral', '(very) useful' and 'don't know'.

Combining the findings of the literature survey, the interviews and the web survey makes it possible to find bottlenecks that may hamper the use of PSS in practice, enabling the identification of lessons that could be applied to remove these bottlenecks. In line with the research approach, the bottlenecks and lessons were divided into categories related to instrument quality, diffusion and user acceptance, although some overlap between the categories was recognized. The bottlenecks were found during analysis of results from the web and literature surveys. These bottlenecks were investigated in more detail during the interviews. The lessons derived from the bottlenecks (for example 'lack of awareness of PSS' led to 'spread the news of PSS') were made more explicit during the interviews, which aimed to distinguish bottlenecks and link them to solutions. Additional literature was used to support and elaborate on the data from the user interviews.

In the following two sections we present some of the bottlenecks and lessons learned. To show which solution should remove which bottleneck, all bottlenecks 
have been marked with a letter so that they can be identified again in the lessons section below. The supply-side bottlenecks are marked with an 's' (s1-s6) and the demand-side bottlenecks are marked with a ' $d$ ' $(\mathrm{d} 1-\mathrm{d} 18)$. For bottlenecks related to both supply and demand, the most suitable marking has been chosen (e.g. see bottlenecks d1 and s6 in the following section).

\section{Bottlenecks}

\section{Supply-Side Bottlenecks}

This section describes supply-side bottlenecks that prevent the widespread use of PSS in practice, most of which have been taken from our literature survey and relate to the instrument quality of PSS.

Our results show the following bottlenecks. First, although a wide range of systems has been described, little insight exists into the features that characterise a PSS. Such insights could be gained from comparative evaluation studies. However, the literature shows only a few attempts to introduce a clear structure into PSS developments (Bishop 1998; Hopkins 1998; Brail and Klosterman 2001; Geertman and Stillwell 2003). Such studies could form a basis for improving the delimitation of the PSS concept as well as being a means of learning valuable lessons about good practice. The lack of adequate comparative evaluations makes it difficult to tell the good systems from the bad systems, and few lessons can be learned for developing PSS and their application (s1).

Second, there is little proof of the actual worth of PSS (s2). Very few real world (experimental) studies have been conducted to find proof of the benefits of PSS or studies that have been undertaken have rarely been presented in the scientific literature. This leads to a situation in which the use of PSS is often defended unconvincingly. To prove the value of PSS, people now refer to scientific experts or literature, using abstract terms such as 'improved planning quality'. They take philosophical approaches to the role of knowledge in planning, or simply refer to their subjective experiences with their own systems. These approaches may convince the technically oriented planners but will not easily convince the less technically oriented who are responsible for making decisions on using PSS.

Third, technology still drives planning instead of the other way round (Batty 2003; s3). Planners and researchers around the world have developed a broad range of systems that are hardly used in practice (Klosterman and Pettit 2005). Many are developed solely for scientific purposes rather than commercial use, do not leave the development laboratories, or are only used once or twice. Inventories show that currently, a large range of PSS exists, but the implementation in spatial planning practice lags far behind the supply of tools (Stillwell et al. 1999; Brail and Klosterman 2001; Geertman and Stillwell 2003).

Fourth, another range of systems is being applied in practice on a broader scale. These systems are often relatively well aligned to planning tasks. Some examples of such systems are CommunityViz (http://www.communityviz.org), Index (http:// www.crit.com), What-If? (http://www.what-if-pss.com) and Maptalk (http://www. mapsup.nl). Many of these systems are available off-the-shelf. Also, these PSS have 
a strong people-support component, which may help to explain their relative success. Nonetheless, usage usually remains limited to within national boundaries (s4), which cannot always be explained by simply referring to differences in planning systems but is likely to be due to the lack of an internationally organised demand-side in planning literature and practice geared towards sharing PSS knowledge and experiences (s5). Other factors which limit the use of PSS beyond national boundaries are the international differences in measurement methods, data storage formats, and models and assumptions underlying the systems.

\section{Demand-Side Bottlenecks}

In contrast to the ample attention given to researching the supply side of PSS in the literature, demand-side research has received much less attention (Geertman 2006). Our empirical results from the survey and interviews provide much more information about demand-side bottlenecks related to instrument quality, diffusion and acceptance. Due to the large amount of overlap in the results from our empirical sources, we describe them in an integrated way in keeping with our three research perspectives. Where sources disagree, we mention this explicitly.

Our empirical results show that from a demand-side perspective, a variety of bottlenecks related to instrument quality, diffusion and user acceptance hinder the use of PSS in practice (d1). The quality of the PSS is an important bottleneck needing significant improvement in terms of usefulness and user-friendliness. In particular, the more advanced PSS do not match user capabilities and planning tasks effectively (d2). Also, while supply focuses on advanced systems, practice demands simpler systems (d3). Furthermore, while many PSS aim to support politicians, they are inadequate in meeting their requirements $(\mathrm{d} 4)$.

The diffusion of PSS to and within planning organisations is characterised by a large degree of friction. This is illustrated by insufficient adoption from the external environment of organisations (d5) and hampered initiatives allowing PSS to diffuse from the bottom-up (d6). Managers often failed to take decisions to adopt PSS (d7), instead following their own top-down strategies without PSS (d8). Managers consider the implementation of PSS to be risky (d9). Furthermore diffusion is hampered by the lack of cooperation between geo-information specialists and planners concerning PSS (d10).

The main bottlenecks concerning user acceptance were a lack of awareness concerning the existence and potential of PSS in planning practice (d11), a lack of experience in using PSS (d12) and a general lack of intention to use PSS by the actors in the planning community (d13). A lack of user friendliness (d14) and usefulness (d15) were also reported as obstacles to user acceptance. Furthermore, organisational support for implementation is often limited (d16) and potential users are insufficiently organised (d17). In addition, data quality problems hinder user acceptance of PSS (d18).

\section{Overview of Bottlenecks}

The supply of and demand for PSS as described in this section indicate that PSS technology is still at an early stage of development. Supply clearly does not meet demand very well due to many different factors related to the instrument quality, 

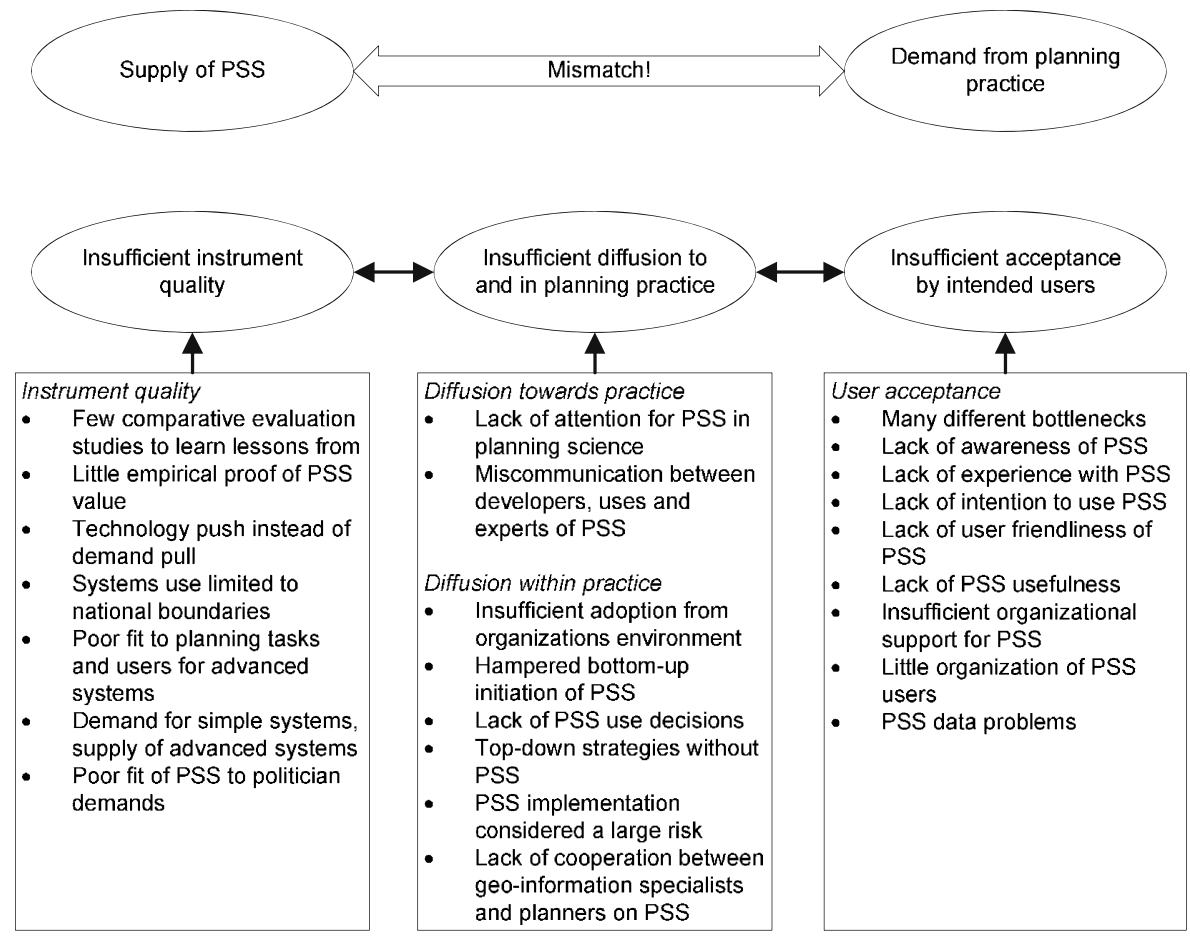

Fig. 3 Factors underlying the mismatch between the supply of and the demand for PSS

diffusion to and in practice, as well as acceptance by the intended users. Figure 3 shows the bottlenecks that were found during our investigations, ordered according to the three perspectives on PSS use described in "Research Strategy and Method" (Vonk et al. 2006). A more extensive description can be found in (Vonk et al. 2005, 2007a, b).

The bottlenecks illustrate a profound miscommunication between PSS developers, users and experts (s6). They do not have a well-developed and shared communication network to exchange knowledge and experiences, and they lack a common vision of the role of PSS. This hampers the learning of lessons that could improve PSS development and application. It also causes PSS development and the PSS themselves to remain largely within the worlds of developers and academics. The following part of this paper illustrates the lessons on how supply of and demand for PSS could be better matched.

\section{Lessons for Good Practice}

\section{Lessons for Enhancing PSS Instrument Quality}

Research Best Practice of PSS-Supported Planning. First, we recommend conducting further research into best practice for PSS supported planning, identifying methods and procedures found to be most effective. Studies should determine which requirements PSS must meet to fit the demands and skills of planners as well as the characteristics of planning tasks. In this way, these studies can contribute to 
improving the instrument quality of PSS. Such a list of requirements can be made for each particular planning task, PSS or application environment. The list of requirements constitutes what can be seen as good or best practice of the application of PSS supported planning (s1).

Analysis of Support Tasks and the Application Environment. We recommend that system developers and geo-information specialists actively start analysing the tasks that may be supported by PSS and the application environments. After all, just as planning practice needs to be made aware of the existence and potential of PSS, system developers and geo-information specialists need to be made aware of the characteristics of planning processes and of the skills and demands of the actors involved in planning. They can use this information to enhance the instrument quality of PSS. To increase the chances of learning valuable lessons from practice, system developers should be open to learning from planners and to engaging in a dialogue with them instead of only communicating their own perspective on the existence and potential of PSS. One example of a way to engage in a dialogue that has been successful for GIS is that software vendors have expanded their business from only selling software to also include consulting services related to geoinformation and applications in planning practice (d2, d4, d14, d15).

Develop Advanced PSS Step by Step. We recommend applying the so-called mixed model, also known as the spiral model, in the development of the more advanced PSS in particular (Boehm 1988; Oriogun 1999; Bharat 2006). Adopting this approach may contribute to success in development and instrument quality. The mixed model is an evolutionary model formulated in 1988 that has become one of the established software development methodologies for complex projects involving many risks. The mixed model is an incremental model in which linear sequences of activities are applied in a staggered fashion. Each increment can incorporate either a prototype part or a completely developed part. Often the first increment produces a core product, addressing identified core needs. The client evaluates the core product, or any increment, and a plan is drawn up for the next increment. This model is useful when complexity, uncertainty, staffing, timing or financial restrictions make it impossible to produce the whole application in one go, which is clearly the case for the more advanced PSS types (Burns and Dennis 1985). Within the context of PSS development, the mixed model often emerges as the only viable and therefore obvious option instead of being the outcome of a deliberate choice for a development model.

A further recommendation is that advanced PSS be developed in close connection with planning practice. While basic PSS can often become directly operational in planning practice, the direct deployment of advanced tools into practice often fails because the tools need to be adjusted to fit the particular application situation. Successful implementation of advanced PSS may require the hiring of external specialists, such as consultants or researchers, who can develop the advanced application into tailor-made applications for the relevant planning organisation. In terms of specialist services, more indirect deployment can help planners to use the products of advanced instruments, such as models, in their planning tasks instead of doing the actual modelling themselves (s5, d18). 
Improving the Quality of Model Based PSS. Many researchers focus on the development of land-use and transportation models, mainly for understanding land-use and transportation changes. The underlying aim of this focus is usually directed towards the application of these systems in urban and regional planning. Examples of such models are UrbanSim, MEPLAN and IRPUD (Simmonds and Echenique 1999). However, in comparison with the enormous attention given to land-use change research (Batty 2005a, b; Van Leeuwen and Timmermans 2006), in planning practice PSS of this kind are rarely used. The instrument quality of the models themselves must first be improved before PSS can become more widely applicable in planning. Many models are not suited to the characteristics of the planning tasks for which they are designed. Furthermore, even the most advanced models simulate remarkably low percentages of developments correctly. Userfriendliness is often totally disregarded. The models are rarely easy-to-use and helpful tools designed for the actors typically involved in planning, but actually tools that can only be operated and understood by a small group of land-use and transport modelling experts. This is partially due to the fact that many models are used for research purposes instead of applications in planning. The What-If? PSS is a positive exception in user-friendliness (Klosterman 2001). In order to improve performance, it is advisable that model researchers compare the performance of different model concepts to determine the best performance standards for particular situations. They should also try out new concepts instead of just adding more variables to existing models. An example is the complex adaptive systems concept, which approaches cities as systems of interdependent, self-organising spatial units. Conventional models assume cities include little or no self-organisation. In recent years model concepts such as these have been receiving increasing attention (Batty 2005a, b; Healey 2007; Miller and Page 2007; s5).

Making PSS Compatible with Regular Office Software. It is recommended that developers and experts strive to improve the fit of existing PSS to the skills of those involved in planning. It is particularly important to make it easier to start using PSS in practice. This could be achieved by improving connections between PSS and the office software often used in planning processes. If PSS are most likely to diffuse bottom-up, it is important that it be easy to try them out. PSS which incrementally build on existing practice and office software already in use for these activities encourage employees to experiment on an informal basis with trial versions and their subsequent incorporation in working processes. Increased emphasis on these issues should improve the instrument quality of PSS (d3).

\section{Lessons for Enhancing PSS Diffusion}

\section{Diffusion to Planning Organisations}

Increased Communication to Practice by Scientists. University scientists are advised to increase their communication with planning practice thus improving instrument quality, acceptance and diffusion of PSS. Universities are currently home to a significant part of the development of advanced PSS and are a good platform for 
actively comparing international developments in PSS. Nonetheless, the results of these activities are poorly communicated to planning practice and intermediary organisations such as consulting firms or government research agencies. This adds to the fact that many practitioners are unaware of PSS developments or even of the existence of PSS. The poor communication with planning practice also leaves many university workers unaware of the actual demands of practitioners, making it difficult to remain up to date about the state of the art of PSS in practice and the development routes actually desired by practitioners.

The communication gap between universities and practice persists because scientists are expected to uphold an independent position unhindered by the realm of policy. They are paid to do cutting-edge work instead of follow practice and are encouraged to publish mainly in international scientific journals which are less accessible to planning practitioners than national professional journals or newspapers. A lack of attention to the world outside academia causes PSS to be developed almost independently of demand. At the same time, development focuses on concerns that differ greatly to those of the demand side. However, in recent years the communication gap between universities and practice has started to decrease in many countries. Universities are increasingly expected to add knowledge dissemination and sharing to their present task of knowledge generation. On the practical level, to increase the communication of knowledge about PSS issues to planning practitioners, scientists must publish more frequently in national journals that are read by planning practitioners. They should also take advantage of other communication channels more easily accessible to planning practitioners. This can enable them to improve awareness of the existence of PSS within the planning community (s3-6, d11).

Intermediate Parties in a Central Role as Initiators of Cooperation and System Integrators. Employees of government research agencies and consultant organisations usually have greater knowledge of and accessibility to planning practice than scientists working within universities. Their intermediate position between policy and research means that they are expected to be better than scientists at getting the actors of the PSS innovation network to engage in cooperative development.

We therefore recommend a major role for intermediate actors such as these in PSS quality improvement. Scientists should focus more on the cutting-edge research while government research institutes could use the resulting knowledge and act as systems integrators. With their knowledge of the demands of planning practice, they could develop PSS from the scientific prototypes and building blocks into useful tools. Consultancies could enhance the development of standard applications in an enterprise ICT environment. This would improve the instrument quality, acceptance and diffusion of PSS. The interviews and literature survey showed several examples of effectively operating intermediate parties. For example, The Netherlands Environmental Assessment Agency (MNP) is a government research agency, successful in its intermediary role in PSS development. The MNP cooperates with universities to further improve their Environment Explorer PSS (land-use model of The Netherlands, http://www.lumos.info), while also learning lessons from the practical application of PSS for the Dutch government. Another good example is the US Department of Energy that initiated cooperative 
development in a community of practice on PSS, including researchers, systems developers and practitioners (originally TCDDM, now http://www.placematters.org; s3-6, d17).

Start a Process of Interactive Learning Among the Actors in the PSS Innovation Network. A process of interactive learning should be initiated among the relevant actors within the PSS innovation network. This learning process involves all the actors that have a role in successful development and application of PSS and takes place through their interaction and cooperation in an organised platform or informal network of contacts (Lundvall 1988). Relevant actors in PSS are scientists, systems developers, government research institutes, consultants, planners, geo-information specialists, managers and executives.

Close cooperation in an experimental setting can be instrumental in learning useful lessons on how best to dedicate systems to users and planning tasks. A great deal remains to be learned, particularly for the more advanced PSS. Involving these many types of actors facilitates knowledge sharing of successful PSS application in all categories instead of just a few. It also increases the chances of successful PSS experiments because no potentially vital information for realising success is lost. For example, in many cases the absence of a systems developer can decrease the chances of successful PSS experimentation because some system programming is usually required in implementing experimental PSS.

In their interactions, they need to find common ground on the development direction of a PSS. As indicated earlier, this requires the development of a common language, common practices and so forth. In any case it requires more than merely the provision of knowledge. These lessons can be used to develop dedicated systems, thereby increasing the overall compatibility of systems. This would enhance the instrument quality, acceptance and diffusion of PSS.

The interview results provide a Dutch example of interactive learning in which government agencies and universities have both been involved. The Lumos project (http://www.lumos.info) aims to develop a spatial modeling toolbox for planning support. It includes the Space Scanner PSS and the Environment Explorer PSS, both of which are land-use models used for spatial planning on the national and provincial levels in The Netherlands. Another example of interactive learning provided by the interview results is the DURP initiative, in which Dutch universities, government agencies, local governments, consultants and professional organisations are all participants (http://www.durp.nl). This initiative aims to establish a platform for digitally exchangeable spatial plans for Dutch municipalities, provinces and ministries. After implementing a shared spatial data format and developing PSS to access the spatial plans, the developed PSS are now becoming implemented in Dutch government organizations (s3-6, d17).

\section{Diffusion in Planning Organisations}

Adopt Knowledge Management and Become a Learning Organisation. Managers should adopt the management paradigm of the learning organisation (Senge 1990) and practice knowledge management (Nonaka and Takeuchi 1995). A learning 
organisation is one which intentionally constructs structures and strategies to enhance and maximise organisational learning (Dodgson 1991). Knowledge management is a discipline within an organisation that ensures that the intellectual capabilities of an organisation are shared, maintained and institutionalised.

This recommendation is largely due to the fact that managing information technology adoption and implementation in complex environments is challenging. To begin with, the demands and opportunities differ across multiple workflow processes and change in different development phases. Another reason is that individuals and organisations in different departments must quickly learn how to work together as a cohesive team. Managing innovation, adoption and implementation of PSS in practice is even more challenging because there seems to be little cooperation or learning among the actors involved in PSS adoption and implementation. The need for control and the need for spontaneity and creativity in complex organisations conflict with one another. This suggests that, at least for a considerable number of the employed workforce, structures and processes oriented around control can essentially shut off workers' natural creativity, having a negative effect on the successful adoption and implementation of PSS (Zhou and George 2003).

Our interview results indicate that adopting the managerial paradigm of the learning organisation could change this, because it stimulates the flow of knowledge to and within organisations. This in turn encourages the innovation, acceptance and diffusion of PSS. The following recommendations illustrate a few specific examples of other ways that planning organisations can become learning organisations besides adopting the management paradigm (s3-5, d7-9, d16).

Instruct Geo-information Specialists as Gatekeepers. Geo-information specialists should act as gatekeepers for PSS. Gatekeepers are those individuals that watch the organisations external environment for developments in their field of specialisation (Rogers 2003). They are often the only ones within the organisation able to follow and evaluate developments in their field of expertise. Therefore they are responsible for signalling promising new developments in their field and bringing these to the attention of their managers. Having geo-information specialists perform the gatekeeper role for PSS would primarily improve the diffusion of PSS.

Geo-information specialists are usually the most qualified to follow and assess geo-ICT related developments within an organisation. Assuming that PSS could be beneficial for planning organisations, geo-information specialists have the important role of scanning the organization's external environment, signalling PSS developments and evaluating their usefulness to the organisation. If managers do not give them the opportunity to do so, the organisation blinds itself to PSS developments that could offer assistance in handling the complexity of planning. The task of scanning the environment entails following relevant activities of government planning agencies, regularly visiting PSS related websites, visiting practice-oriented conferences, maintaining a network with colleagues in other planning organisations and so on.

Geo-information specialists could be more effective if they realise that they are important to the organisation as often the only connections to PSS developments in the external environment. In order to effectively translate planner demands into the opportunities that PSS can provide, geo-information specialists should scan the 
internal environment in addition to the external environment. This would better enable them to make good matches between planner demands and PSS opportunities. This can be achieved by maintaining close formal and informal contact with other departments that use their products and possibly by getting involved in their projects. Managers have the task of convincing geo-information specialists of their innovation responsibility and helping them to tap into their creativity. The interviews showed that geo-information specialists operated in this way in the Dutch province of Overijssel, one of the success stories in the organisational development of PSS. In this organisation, geo-information technologies have diffused from the bottom up from the start (s3, d5).

Appoint an Innovation Manager. We recommend that managers appoint an innovation manager to take up the role of championing PSS and other information technologies for policy support. The innovation manager has the task of boosting an organisation's innovativeness. An important task is to bring promising, often technological developments to the attention of managers, thereby enabling them to respond flexibly to a changing environment. Whereas regular employees find it very difficult to inform managers of new ideas, innovation managers are usually members of the organization's management board. Those most suited to actively championing PSS are those individuals possessing the charisma and persuasive powers needed to bring promising new ideas from the lowest level of the organisation all the way to the boardroom, and even all the way to adoption and implementation decisions. Having champion characteristics helps innovation managers to be effective in their work (Rogers 2003). This can aid planning organisations in becoming learning organisations and improve PSS acceptance and diffusion. This role requires the innovation manager to bring the PSS further into the organisation closer to full utilisation of the opportunities provided by PSS. To this end, the innovation manager must show planners how useful PSS an be in their daily activities. Likewise, the innovation manager must move other managers to the decision on whether to adopt a PSS or continue experimentation with its application. A useful means to achieve support is to make the business case for PSS adoption. If managers do not appoint an innovation manager first, the geo-information specialists will have to perform the roles of both PSS gatekeeper and champion. For the latter role, geo-information specialists must have leadership characteristics. For the champion role, we recommend geo-information specialists to demonstrate the benefits of PSS to their managers and planners with examples of PSS applications that run parallel to existing regular projects and that are also as realistic as possible in other ways. This is a good way to connect to the realities of planners and managers. It can also provide an alternative solution to an existing problem, making the benefits clear while planners and managers have their attention focused on that particular problem. It is crucial to keep things as realistic as possible so that planners and managers can gain insight into the consequences, benefits and risks of a potential decision to adopt. The use of illustrations that are unconnected to existing projects, hypothetical problems for the area governed, or even problems for other areas, is less likely to create interest.

The interviews showed several examples of innovation managers at work in the Dutch provinces. The Dutch province of Noord-Brabant, which was among the most 
successful organisations in implementing PSS involved in our research, had just assigned an innovation manager with champion qualities at the time of the interviews. The province of Limburg, which was in an earlier stage of PSS usage, had also appointed an innovation manager with the main task of organising the spatial data that could serve as a basis for further analysis-oriented developments (s3, d6).

Facilitate Cooperation Between Planners and Geo-Information Specialists. As close cooperation between planners and geo-information specialists is essential for the successful application of PSS, we recommend managers in general and the innovation managers in particular to bring planners and geo-information specialists together $(\mathrm{s} 3-4, \mathrm{~d} 10)$.

Lessons for Enhancing Acceptance of PSS by Intended Users

Measure the Benefits of PSS Application. Scientists must develop methodologies to effectively measure the benefits of applying the diversity of PSS. Such demonstrable benefits are a prerequisite for the widespread acceptance of PSS types. At present, not enough is known about how the best methods of measuring and expressing the benefits of most PSS. Real experiments that could demonstrate the benefits of PSS would provide valuable insights, but studies such as these have not yet been conducted specifically for PSS as far as we know, although benefit studies have been carried out for related (geo)-information technologies (Budic 1994; Nedovic-Budic 1998; Batenburg and Bongers 2001; s2-5, d13).

Spread the News of PSS to Increase Awareness. Those users, system developers and researchers that are already aware of the existence and potential of PSS should spread the news of PSS more actively and through the appropriate communications channels. This would influence widespread awareness of PSS positively, making the PSS message more suitable for being picked up on and appreciated by employees of planning organisations. By generating awareness they can make others aware of the opportunities PSS application can provide in possibly improving their planning processes. This can alleviate the bottleneck of lack of awareness of the existence and potential of PSS. The difficulty of generating a (more) realistic image of PSS is that the relevant actors typically have different backgrounds and responsibilities, giving them different views of PSS. Each type of employee of a planning organisation (geoinformation specialist, planner, manager, etc.) may respond to different aspects of PSS or different modes of presentation of PSS. This is why many planners and managers fail to appreciate the opportunities suggested by geo-information specialists.

One way to overcome this difficulty is to generate awareness incrementally upwards through the hierarchy in an organisation. A first step would be for systems developers to increase awareness among geo-information specialists in planning organisations by reporting about the opportunities at practitioner-oriented conferences, publishing about their systems on the Internet, or by contacting geoinformation specialists directly. Geo-information specialists can then inform the innovation manager or generate awareness among planners, who can inform executives within the planning organisations they work for. 
Another way to overcome difficulties in generating awareness is to form focus groups of innovators with different backgrounds and responsibilities, aimed at developing examples of PSS application to a planning problem currently faced by the organisation. Systems developers could assist geo-information specialists and innovative planners in developing good examples of PSS application, which they could then use to convince other planners and executives of the worth of PSS. The interview results indicated that this was an effective means of overcoming background differences.

The awareness generating actions described above should not be stopped after a single failed attempt. Innovation in complex user environments with heterogeneous realities of the involved actors may be a process that takes time and have varying levels of success, depending as it does on factors that awareness generators often have only limited control. The underlying reason is that innovation does not simply require the creation of new knowledge, but also the creation of new language, practices and meaning (Moss 2001). During these processes, employees of planning organisations may gradually organise themselves into stable patterns of activity and communication that provide them with a common frame of reference to PSS and their usage. The development of a common language in a complex user environment may be time-consuming. It is therefore important that awareness generation continue until sufficient new language, practices and meaning have been created to adopt PSS. Awareness generation through knowledge provision alone is not enough. Communicators of the PSS message should also focus on ensuring that the knowledge provided is also understood. The organisation scientist Karl Weick (2001) describes this type of organisational communication that focuses on understanding as 'sensemaking' (s4-5, d11, d13).

Generate Positive Experiences by Applying Best Practice. We recommend applying 'best practice' of development and application of PSS. Best practice involves methods and procedures found to be most effective. Their use stimulates the generation of positive experiences that help to alleviate the primary bottleneck preventing the widespread usage of PSS: lack of experience. Best practice includes those development or application settings that have proven successful. PSS practice has often only provided proof of the success of a few cases, in which 'best practice' tended to be in fact 'good practice'. Applying good or best practice implies using high standard systems as well as making sure that none of the known organisational hazards to successful usage indicated in Fig. 3 occur.

As for the organisational hazards, we recommend to follow PSS usage recommendations as described in the previous section. Regarding usage of high standard systems we recommend focusing more attention on world-class systems such as CommunityViz, What-If? or Index.

Despite the opportunities provided by PSS, planning practice is currently hardly aware of their existence. The literature survey showed a good example of a Dutch consultancy firm that benefited directly from these world-class systems. They purchased components of the PSS CommunityViz, to implement in their own PSS (http://www.communityviz.com; http://www.mapsup.nl). This furnished them with a world-class PSS that is applicable in Dutch planning circumstances. They incorporated the CommunityViz components in their own standard methodology which they use to support several dozens of (mainly municipal) planning cases a 
Table 1 Bottlenecks preventing the successful integration of PSS into planning practice, lessons to prevent or take away these bottlenecks, and actors who can apply these lessons, regarded from the perspectives of instrument quality, diffusion and user acceptance

\begin{tabular}{|c|c|c|}
\hline & Bottleneck & Lessons \\
\hline & \multicolumn{2}{|l|}{ General } \\
\hline \multirow[t]{2}{*}{ D1 } & Many different bottlenecks & \\
\hline & \multicolumn{2}{|l|}{ Instrument quality } \\
\hline S1 & $\begin{array}{l}\text { Few comparative evaluation } \\
\text { studies to learn lessons from }\end{array}$ & $\begin{array}{l}\text { Research best-practices of PSS supported } \\
\text { planning }\end{array}$ \\
\hline $\mathrm{S} 2$ & $\begin{array}{l}\text { Little empirical proof of PSS } \\
\text { value }\end{array}$ & Measure benefits of PSS application \\
\hline S3 & $\begin{array}{l}\text { Technology push instead of } \\
\text { demand pull }\end{array}$ & $\begin{array}{l}\text { Most diffusion and user acceptance } \\
\text { lessons }\end{array}$ \\
\hline S4 & $\begin{array}{l}\text { Systems use limited to } \\
\text { (national) boundaries }\end{array}$ & $\begin{array}{l}\text { Most diffusion and user acceptance } \\
\text { lessons }\end{array}$ \\
\hline \multirow[t]{3}{*}{ D2 } & $\begin{array}{l}\text { Poor fit to planning tasks and } \\
\text { users for advanced systems }\end{array}$ & $\begin{array}{l}\text { Analyse support tasks and the application } \\
\text { environment }\end{array}$ \\
\hline & & Develop advanced PSS step by step \\
\hline & & $\begin{array}{l}\text { Improving the quality of model-based } \\
\text { PSS }\end{array}$ \\
\hline D3 & $\begin{array}{l}\text { Demand for simple systems, } \\
\text { supply of advanced systems }\end{array}$ & $\begin{array}{l}\text { Making PSS compatible with regular } \\
\text { office software }\end{array}$ \\
\hline D4 & $\begin{array}{l}\text { Poor fit of PSS to politician } \\
\text { demands }\end{array}$ & $\begin{array}{l}\text { Analyse support task and the application } \\
\text { environment }\end{array}$ \\
\hline
\end{tabular}

Actor

All

Researchers

Researchers

All

All

Developers

Developers

Developers

Developers

Developers

\section{Diffusion to planning organizations}

S5 Lack of attention for PSS in Most diffusion and user acceptance All planning science

S6 Miscommunication between PSS developers, users and experts

\section{lessons}

Increased communication to practitioners by scientists
Intermediate parties in a central role as initiators of cooperation and systems integrators
Start a process of interactive learning among the actors in the PSS innovation network

All
Researchers

Intermediates

Intermediates

Users

Users

Users

become a learning organisation

Adopt knowledge management and Users

become a learning organisation

Adopt knowledge management and Users

become a learning organisation

Facilitate cooperation between planners Users and geo-information specialists

Spread the news of PSS to increase awareness
All 
Table 1 (continued)

\begin{tabular}{|c|c|c|c|}
\hline & Bottleneck & Lessons & Actor \\
\hline & & $\begin{array}{l}\text { Increased communication to practice } \\
\text { side by scientists }\end{array}$ & Researchers \\
\hline D12 & Lack of experience with PSS & $\begin{array}{l}\text { Generate positive experiences by applying } \\
\text { best practices }\end{array}$ & Developers \\
\hline D13 & Lack of intention to use PSS & Most user acceptance lessons & All \\
\hline D14 & $\begin{array}{l}\text { Lack of user friendliness } \\
\text { of PSS }\end{array}$ & $\begin{array}{l}\text { Analyse support task and the application } \\
\text { environment }\end{array}$ & Developers \\
\hline D15 & Lack of PSS usefulness & $\begin{array}{l}\text { Analyse support tasks and the application } \\
\text { environment }\end{array}$ & Developers \\
\hline D16 & $\begin{array}{l}\text { Insufficient organisational } \\
\text { support for PSS }\end{array}$ & $\begin{array}{l}\text { Adopt knowledge management and } \\
\text { become learning a organisation }\end{array}$ & Users \\
\hline \multirow[t]{2}{*}{ D17 } & $\begin{array}{l}\text { Little organisation among PSS } \\
\text { users }\end{array}$ & $\begin{array}{l}\text { Intermediate parties in a central role as } \\
\text { initiators of cooperation and system } \\
\text { integrators }\end{array}$ & Intermediates \\
\hline & & $\begin{array}{l}\text { Start a process of interactive learning } \\
\text { among the actors in the PSS innovation } \\
\text { network }\end{array}$ & Intermediates \\
\hline D18 & PSS data problems & Develop advanced PSS step by step & \\
\hline
\end{tabular}

year. A useful reference containing information on 'best practice' of PSS application is the website www.placematters.org, a knowledge base on PSS accessible to planning practitioners which contains examples of PSS, their applications in practice, and guidelines for PSS application (s3-5, d12-d13).

\section{Overview of Bottlenecks, Lessons and Actors}

Table 1 provide an overview of the bottlenecks preventing the successful integration of PSS into planning practice from "Bottlenecks", the lessons that
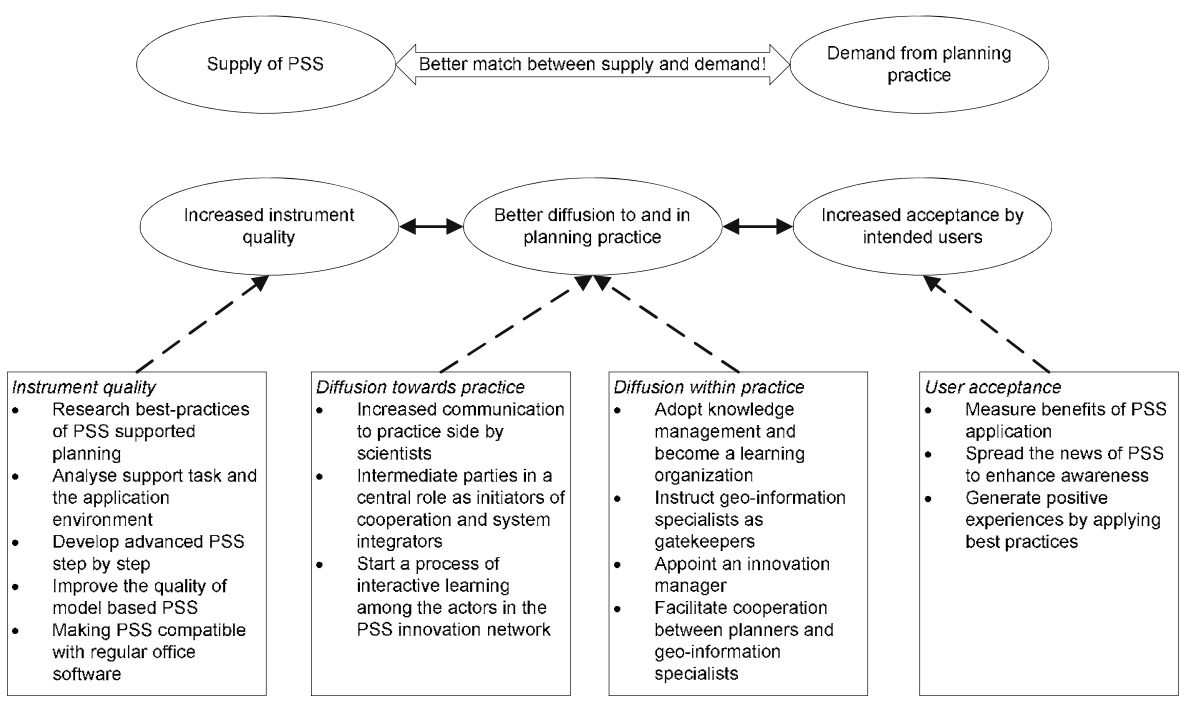

Fig. 4 Lessons to enhance usage of PSS in spatial planning practice 
apply to the bottlenecks from "Lessons for Good Practice" and the actors who can apply the lessons. For more extensive descriptions, the markings s1-6 and d1-18 can be referred to above in "Bottlenecks" and "Lessons for Good Practice" of this paper.

Figure 4 shows how the lessons can be used to improve the match between supply of and demand for PSS and to more effectively integrate PSS into planning practice. These lessons can improve the instrument quality of PSS, diffusion to practice and acceptance by intended users.

\section{Conclusions and Recommendations}

The previous sections show that although we are still just beginning to gain insight into how to effectively integrate PSS in planning practice, a number of useful lessons have been learned that are oriented towards improving instrument quality, acceptance and diffusion of PSS. The actors that correspond to the lessons can apply them in order to break the vicious circle which PSS-technology is stuck in. This is necessary to decrease the mismatch between the demand for and the supply of PSS and ultimately improve planning with PSS.

Although the lessons were partially based upon experiences from Dutch organisations, it is our opinion that many have a much broader applicability. The fact that many lessons from the Dutch planning organisations in the study were confirmed by expert surveys and the literature supports this view. The lessons on acceptance and diffusion also apply in a more general context, because the interviewed employees represent archetypes that are very common in planning organisations in western and non-western societies. The structure and culture of the organisations in this study are quite common in government organisations. It is true that specific situations must always be carefully evaluated, but we believe that many of these lessons can be generalised.

We recommend that those involved in development, use and research of PSS employ the lessons described in this paper in their efforts to improve PSS and their practical application. In this way, PSS may prove valuable tools for enhancing the role of information and knowledge in planning, thereby enabling and facilitating knowledge-based planning.

In applying the lessons, a technocentric approach must be avoided. With many underused PSS available, we recommend focusing on the demand side, which is the planning community. A demand side oriented approach that would account for all aspects of the application environment of PSS and the organisation using it, one that searches combined interests instead of only pushing forward the technology, is much more promising to enhance PSS use in planning practice.

Open Access This article is distributed under the terms of the Creative Commons Attribution Noncommercial License which permits any noncommercial use, distribution, and reproduction in any medium, provided the original author(s) and source are credited. 


\section{References}

Anthony, R. (1965). Planning and control systems: A framework for analysis. division of research, graduate school of business administration. Cambridge, MA: Harvard University.

Batenburg, R., \& Bongers, F. (2001). The role of GSS in participatory policy analysis: a field experiment. Information \& Management, 39(1), 15-30.

Batty, M. (1979). Progress, success and failure in urban modelling. Environment and Planning A, 11(8), $863-878$.

Batty, M. (1995). Planning support systems and the new logic of computation. Regional Development Dialogue, 16(1), 1-17.

Batty, M. (2003). Planning support systems: Technologies that are driving planning. In S. Geertman, \& J. Stillwell (Eds.), Planning support systems in practice (pp. v-viii). Berlin: Springer.

Batty, M. (2005a). Cities and complexity, understanding cities with cellular automata, agent-based models, and fractals. Cambridge, MA: MIT.

Batty, S. (2005b). Proceedings of the Computers in Urban Planning and Urban Management Conference, London, UK, University College London.

Bharat, B. (2006). The spiral model, IT project management solutions. EzineArticles. Retrieved April 10 2008, from http:/ezinearticles.com/?The-Spiral-Model:-IT-Project-Management-Solutions\&id=362625.

Bishop, I. (1998). Planning support: hardware and software in search of a system. Computers Environment and Urban Systems, 22(3), 189-202.

Boehm, B. (1988). A spiral model of software development and enhancement. IEEE Computer, 21(5), 61-72.

Borins, S. (2000). What border? Public management innovation in the United States and Canada. Journal of Public Policy Analysis and Management, 19(1), 46-74.

Borins, S. (2001). The challenge of innovating in government. Toronto: University of Toronto.

Brail, R. \& Klosterman, R. (Eds.) (2001). Planning support systems, integrating geographic information systems, models and visualization tools. Redlands, CA: Esri.

Budic, Z. (1994). Effectiveness of geographic information systems in local planning. Journal of the American Planning Association, 60(2), 244-264.

Burns, R., \& Dennis, A. (1985). Selecting the appropriate software development methodology. DATA BASE, 17(1), 19-24.

Croswell, P. (1991). Obstacles to GIS implementation and guidelines to increase the opportunities for succes. URISA Journal, 3(1), 43-56.

Dammers, E., Kranendonk, R., Smeets, P., Adolfse, L., Van Woerkum, C., Horrevoets, M., et al. (1999). Innovation and learning-Knowledge management and rural innovation. The Hague: National Council for Agricultural Research (NLRO).

Dodgson, M. (1991). Technology, learning, technology strategy and competitive pressures. Brittish Journal of Management, 2(3), 132-149.

Friedman, J. (1987). Planning in the public domain: From knowledge to action. Princeton: Princeton University Press.

Geertman, S. (2006). Potentials for planning support: a planning-conceptual approach. Environment and Planning B, 38(6), 863-880.

Geertman, S. \& Stillwell, J. (Eds.) (2003). Planning support systems in practice. Advances in spatial science. Berlin: Springer.

Geertman, S., \& Stillwell, J. (2004). Planning support systems: an inventory of current practice. Computers Environment and Urban Systems, 28(4), 291-310.

Hall, P. (1975). Urban and regional planning. Harmondsworth, UK: Penguin Books.

Healey, P. (2007). Urban complexity and spatial strategies, towards a relational planning for our times. London: Routledge.

Hopkins, L. (1998). Progress and prospects for planning support systems. Environment and Planning B: Planning and Design, Anniversary Issue, 29-31.

In 't Veld, R. (Ed.) (2000). Willingly and knowingly, the roles of knowledge on nature and environment in policy processes. Utrecht, The Netherlands: Lemma.

Innes, J., \& Simpson, D. (1993). Implementing GIS for planning. Journal of the American Planning Association, 59(2), 230-236.

Klosterman, R. (1997). Planning support systems: a new perspective on computer-aided planning. Journal of Planning Education and Research, 17(1), 45-54. 
Klosterman, R. (2001). The what if? Planning support system. In R. Brail, \& R. Klosterman (Eds.), Planning support systems, integrating geographic information systems, models and visualization tools (pp. 263-284). Redlands: ESRI.

Klosterman, R., \& Pettit, C. (2005). Guest editorial: an update on planning support systems. Environment and Planning $B, 32(4), 477-484$.

Lee, D. (1973). Requiem for large-scale models. Journal of the American Planning Association, 39(3), 163-178.

Lee, D. (1994). Retrospective on large-scale urban models. Journal of the American Planning Association, $60(1), 35-40$.

Lundvall, B. (1988). Innovation as an interactive process: from user-producer interaction to the national system of innovation. In G. Dosi, C. Freeman, R. Nelson, G. Silverberg, \& L. Soete (Eds.), Technical change and economic theory (pp. 349-369). London: Pinter Publishers.

Miller, J., \& Page, S. (2007). Complex adaptive systems, an introduction to computational models of social life. New Jersey: Princeton University Press.

Minzberg, H. (1981). The structuring of organizations: A synthesis of research. New York: Prentice-Hall.

Moss, M. (2001). Sensemaking, complexity and organizational knowledge. The Journal of Knowledge and Process Management, 8(4), 1-16.

Nedovic-Budic, Z. (1998). The impact of GIS technology. Environment and Planning B: Planning and Design, 25(5), 681-692.

Nonaka, I., \& Takeuchi, H. (1995). The knowledge-creating company: How Japanese companies create the dynamics of innovation. Oxford: Oxford University Press.

Openshaw, S. (1979). A methodology for using models for planning purposes. Environment and Planning A, 11(8), 879-896.

Oriogun, P. (1999). A survey of Boehm's work on the spiral models and COCOMO II, towards software development process quality improvement. Software Quality Journal, 8(1), 53-62.

Rogers, E. (2003). Diffusion of innovations. New York: Free Press.

Senge, P. (1990). The fifth discipline: The art and practice of the learning organization. New York: Currency Doubleday.

Simmonds, D., \& Echenique, M. (1999). Review of land use/transport interaction models. Retrieved April 10, 2008, from http://www.dft.gov.uk/pgr/economics/sactra/srd/rolu/reviewoflandusetransportinte3145.

Stillwell, J., Geertman, S., \& Openshaw, S. (1999). Geographical information and planning. Berlin: Springer.

Van Leeuwen, J., \& Timmermans, H. (Eds.) (2006). Innovations in design and decision support systems in architecture and urban planning. Dordrecht, The Netherlands: Springer.

Vonk, G., Geertman, S., \& Schot, P. (2005). Bottlenecks blocking widespread usage of planning support systems. Environment and Planning A, 17(5), 909-924.

Vonk, G., Geertman, S., \& Schot, P. (2006). Usage of planning support systems: Combining three approaches. In J. Van Leeuwen, \& H. Timmermans (Eds.), Innovations in design and decision support systems in architecture and urban planning (pp. 263-274). Dordrecht, The Netherlands: Springer.

Vonk, G., Geertman, S., \& Schot, P. (2007a). New technologies stuck in old hierarchies: an analysis of the diffusion of geo-information technologies in Dutch planning organizations. Public Administration Review, 67(4), 745-756.

Vonk, G., Geertman, S., \& Schot, P. (2007b). A SWOT-analysis of planning support systems. Environment and Planning A, 39(7), 1699-1714.

Weick, K. (2001). Making sense of the organization. Malden, MA: Blackwell.

Zhou, J., \& George, J. (2003). Awakening employee creativity: the role of leader emotional intelligence. The Leadership Quarterly, 14(4-5), 545-568. 